\title{
PAGAMENTO POR SERVIÇOS AMBIENTAIS (PSA) COMO FERRAMENTA EFETIVA À APLICABILIDADE DO CÓDIGO FLORESTAL BRASILEIRO: UMA PROPOSTA COMBATIVA AO PROJETO DE LEI No. 1876/99. RELATOS DA EXPERIÊNCIA PIONEIRA DE PSA NO MUNICÍPIO DE LONDRINA - PR
}

\section{PAYMENT FOR ENVIRONMENTAL SERVICES (PES) AS EFFECTIVE TOOL TO APPLICABILITY OF BRAZILIAN FOREST CODE: A FOUGHT PROPOSAL TO THE BILL NO.1876/99. REPORTS FROM THE EXPERIENCE OF PIONEER PES IN LONDRINA-PR}

\begin{abstract}
RESUMO: A finalidade do presente estudo é delinear as principais alterações previstas no Projeto de Lei n ${ }^{\circ}$. 1876/1999, em trâmite na Câmara dos Deputados, que pretende revogar o Código Florestal brasileiro (Lei $n^{\circ}$. 4.771/1965). O diagnóstico das inúmeras discrepâncias trazidas pelo substitutivo de lei em relação à lei florestal em vigor permite consignar a enormidade de lesões a que a biodiversidade do país estará exposta. Neste cenário, os Pagamentos por Serviços Ambientais mostram-se um meio efetivo à tutela das reservas florestais e das vegetações ciliares do país, já que sua implementação tem contribuído para desmistificar a exeqüibilidade da lei ambiental. Para tanto, expõe-se a experiência pioneira e frutífera de incentivo a boas práticas agrícolas a partir da remuneração pelos serviços ecológicos na cidade de Londrina- Paraná, enfatizando conjuntamente ao final, a imprescindibilidade de políticas públicas e de fomento à sociedade civil organizada para que haja plena efetividade do Código Florestal vigente.
\end{abstract}

Palavras Chave: Projeto de Lei 1876/99; Código Florestal; Pagamento por Serviços Ambientais; Programa de Londrina-PR.

\begin{abstract}
The purpose of this study is to outline the main changes in the Draft Law. 1876/1999, pending in the House of Representatives that would repeal the Brazilian Forest Code (Law no. 4.771/1965). The diagnosis of the numerous discrepancies introduced by the substitution of law in relation to the forestry law in force allows consign the enormity of the damage that the country's biodiversity will be exposed. In this scenario, the Payments for Environmental Services prove to be an effective means for protection of forest reserves and riparian vegetation of the country, since their implementation has helped to demystify the feasibility of environmental law. To do so, exposes himself to pioneering and fruitful of encourage good farming practices from the remuneration for environmental services in Londrina, Parana, emphasizing together in the end, the crucial need for public policy and fostering to civil society so that there is full realization of the Forestry Code in force.
\end{abstract}

Keywords: Bill 1876/99; Forest Code; Payment for Environmental Services; PAS in Londrina-PR.

\footnotetext{
${ }^{1}$ Bacharel em Direito pela Universidade Estadual de Londrina/PR. Pós-graduanda em Direito Constitucional pela Universidade Estadual de Londrina/PR. Advogada militante na área ambiental. Membro da ONG MAE Meio Ambiente Equilibrado da cidade de Londrina/PR.
} 


\section{INTRODUÇÃO}

A sociedade brasileira tem sido espectadora de diversos debates que envolvem o futuro do Código Florestal (Lei nº. 4.771/1965) e a possibilidade de sua substituição pelo Projeto de Lei ${ }^{\circ}$. 1876/99, cujo relator é o deputado federal Aldo Rebelo (PC do B/SP). Referido substitutivo, aprovado no último dia 06 de julho de 2010 pela comissão especial da Câmara dos Deputados, traz em seu bojo intricadas disposições acerca das Áreas de Preservação Permanente (APP) e de Reserva Legal (RL), bem como soluções imediatistas para o descumprimento da lei ocorrido até a atualidade.

Esmiúçam-se nestas linhas diversos dispositivos da proposta supracitada que vão de encontro às concepções abarcadas pelo Código Florestal brasileiro, tais como a biodiversidade e a sadia qualidade de vida, assegurados constitucionalmente. Tais evidências permitem constatar que uma significativa parcela ruralista brasileira, em nome dos interesses agrário-econômicos nacionais, tem procurado resolver suas irregularidades ambientais através do Poder Legislativo.

Assim, pretende-se inserir neste relevante debate os Pagamentos por Serviços Ambientais como um instrumento perspicaz à concretização da norma florestal vigente, já que citado mecanismo vem sendo adotado por diversas regiões do Brasil, apoiando-se à noção de que o serviço ambiental vincula-se à necessidade de manter a capacidade da natureza de reproduzir as condições ambientais que sustentam a vida do planeta.

\section{O PROJETO DE LEI Nº 1876/99 - TRAMITAÇÃO}

O Projeto de Lei nº $1876 / 99$ de autoria de Sérgio Carvalho (PSDB-RO) possui na atualidade dez propostas de lei de semelhante teor apensadas ao seu volume ${ }^{2}$, no qual se pretende, genericamente, revogar o Código Florestal vigente (Lei nº 4.771/1965), através da redefinição das Áreas de Preservação Permanente, dos limites geográficos, da Reserva Legal, e da exploração Florestal, além de prescrever sobre a proteção da vegetação nativa. No ano de 2009 foi criada uma comissão especial ${ }^{3}$ na Câmara dos Deputados com o intuito de analisar o Projeto de Lei supracitado e o seu relatório, organizado pelo deputado federal Aldo Rebelo (PC do B-SP).

Em fevereiro de 2009 algumas audiências públicas foram realizadas em diversos estados da federação (Goiás, São Paulo, Minas Gerais, Tocantins, Acre, Amazonas, Roraima)

\footnotetext{
${ }^{2}$ Projetos de Lei apensados ao PL 1876/99: PL 4524/2004; PL 4091/2008; PL 4395/2008; PL 4619/2009; PL 5226/2009; PL 5367/2009; PL 5898/2009; PL 6238/2009; PL 6313/2009 e PL 6732/2010.

${ }^{3}$ Integra a Comissão Especial as comissões de: Minas e Energia; Desenvolvimento Urbano; Desenvolvimento Econômico, Indústria e Comércio; Trabalho, de Administração e Serviço Público; Agricultura, Pecuária, Abastecimento e Desenvolvimento Rural; Meio Ambiente e Desenvolvimento Sustentável; Finanças e Tributação e Constituição e Justiça e de Cidadania.
} 
Pagamento por serviços ambientais (PSA) como ferramenta efetiva à aplicabilidade do Código Florestal brasileiro: uma proposta combativa ao projeto de lei $\mathrm{n}^{\circ}$. 1876/99. Relatos da experiência pioneira de PSA no município de Londrina-PR

com o fito de colher maiores opiniões e depoimentos de interessados no debate, como produtores rurais, deputados federais, Ministério Público, cientistas e pesquisadores, representantes de universidades, membros de organizações não-governamentais, movimento dos trabalhadores rurais sem-terra, dentre outros. Apesar da metodologia adotada pela referida Comissão ter, a princípio, a intenção de incluir maiores críticas e sugestões ao PL 1876/99, não houve, na prática, uma abertura coerente à comunidade científica para comentar e embasar cientificamente as propostas trazidas pelo documento legislativo ${ }^{4}$, o que propiciou um conglomerado de polêmicas ao redor da pretensa proposta.

Ademais, não se configurou ampla extensão da discussão à sociedade, que, alheia integralmente, percebeu a relevância da questão apenas no presente ano, quando a

Comissão Especial aprovou, por 13 votos a 55, o relatório final do deputado Aldo Rebelo, em 6 de julho de 2010.

A votação do PL 1876/99 pela plenária da Câmara dos Deputados ainda não ocorreu em detrimento do conturbado período eleitoral. A continuidade das discussões e votações reinicia-se com os novos mandatos à presidência, governos, senado, câmara e assembléias legislativas, que se mostrarão responsáveis pelos próximos acontecimentos relacionados à importante questão em comento.

\section{MUDANÇAS CONTIDAS NA PROPOSTA}

O substitutivo de lei traja em suas linhas significativas alterações no tocante às Áreas de Preservação Permanente (APP), Reserva Legal e regularização ambiental, além de abarcar inéditas previsões acerca de áreas urbanas e rurais consolidadas.

Num primeiro momento, convém respaldar as alterações contidas em relação às Áreas de Preservação Permanente ${ }^{6}$ que, caso seja sancionado o PL 1876/99, deixarão de serem como tal os topos de morros, montes, montanhas e serras (contidos no artigo $2^{\circ}$, alínea "d" do Código Florestal); as restingas, em uma faixa de 300 (trezentos) metros a partir da linha preamar máxima (art. $2^{\circ}$, alínea “f”, idem); locais com altitude superior a 1.800 (um mil e oitocentos) metros

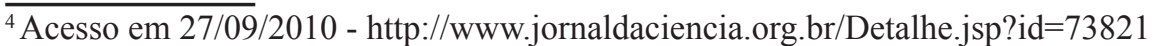

${ }^{5}$ Os deputados federais que votaram a favor do PL 1876/99: Anselmo de Jesus (PT-RO); Homero Pereira (PRMT); Luis Carlos Heinze (PMDB-PR); Moacir Micheletto (PMDB-PR); Paulo Piau (PPS-MG); Valdir Colatto (PMDB-SC); Hernandes Amorim (PTB-RO); Marcos Montes (DEM-MG); Moreira Mendes (PPS-RO); Duarte Nogueira ( PSDB-SP); Aldo Rebelo (PC do B- SP); Reinhold Stephanes (PMDB-PR); Eduardo Seabra (PTBAP). Deputados federais que votaram contra o PL 1876/99: Dr. Rosinha (PT-PR); Ricardo Tripoli (PSDB-SP); Rodrigo Rollemberg (PSB-DF); Sarney Filho (PV-MA); Ivan Valente (PSOL-SP).

${ }^{6}$ Lei $\mathrm{n}^{\mathrm{o}}$. 4.771/1965, art. $1^{\circ}, \S 2^{\circ}$, II: “Área de preservação permanente: área protegida nos termos dos arts. $2^{\circ} \mathrm{e}$ $3^{\circ}$ desta Lei, coberta ou não por vegetação nativa, com a função ambiental de preservar os recursos hídricos, a paisagem, a estabilidade geológica, a biodiversidade, o fluxo gênico de fauna e flora, proteger o solo e assegurar o bem-estar das populações humanas."
} 
(art.2, alínea “h”, idem); as acumulações naturais ou artificiais de água com superfície inferior a 1 (um) hectare (incluído no artigo $3^{\circ}, \S 4^{\circ}$ do PL 1876/99).

Também foi trazida pela proposta de lei em análise a distinção entre nascente e olho d' água que são considerados sinônimos pelo Código Florestal. Citada distinção poderá permitir a interferência em Áreas de Preservação Permanente situadas ao redor de nascentes intermitentes?

Ainda no tocante às áreas marginais, pretende o substitutivo de lei que os Estados possam, no âmbito do programa de regularização ambiental, dispensar a recuperação das Áreas de Preservação Permanente (APPs) localizadas em áreas rurais consolidadas. Isto significa que, até que os programas de regularização sejam implantados pelos Estados ou Distrito Federal, qualquer propriedade rural que tenha sua Área de Preservação Permanente suprimida não será mais obrigada a recuperá-la.

O trato em relação às áreas consolidadas não abarcou apenas as propriedades rurais, mas, sobretudo, as urbanas. O artigo $2^{\circ}$, inciso IV, do PL 1876/99 determinou os espaços urbanos consolidados como áreas definidas pelo Plano Diretor Municipal e que tenham, no mínimo, três destes requisitos: drenagem de águas pluviais urbanas; esgotamento sanitário; abastecimento de água potável; distribuição de energia elétrica; ou limpeza urbana, coleta e manejo de resíduos sólidos. Observa-se que os critérios estabelecidos para reconhecer a área urbana consolidada não incluem a exigência de que esta seja habitada, permitindo a criação destas áreas a qualquer tempo, independentemente de ocupação ${ }^{8}$.

Além disso, a metragem correspondente às faixas das matas ciliares cogita integral alteração, sendo que, as margens de rios cuja largura atual mínima é de 30 (trinta) metros perfarão apenas 15 (quinze) metros, podendo esta extensão ser reduzida em até 50\% (cinqüenta por cento) pelos estados-membros, o que implica que, na prática, a mata ciliar mínima de proteção aos rios possa ser de apenas 7,5 (sete e meio) metros ${ }^{9}$.

No que concerne à Reserva Lega ${ }^{10}$, propõe-se pelo substitutivo eliminar a exigência

\footnotetext{
${ }_{7}^{7}$ Enquadram-se nestes casos as diversas restrições impostas à intervenção ou supressão em APP de nascentes previstas na Resolução CONAMA 369/2006. Considerações extraídas da Nota Técnica expedida pela $4^{\text {a }}$ Câmara de Coordenação e Revisão do Ministério Público Federal acerca do Substitutivo de Lei nº ${ }^{\circ}$ 1876/1999, em 28 de junho de 2010.

${ }_{8}^{8}$ Nota Técnica expedida pela $4^{\mathrm{a}}$ Câmara de Coordenação e Revisão do Ministério Público Federal acerca do Substitutivo de Lei $n^{\circ} .1876 / 1999$, em 28 de junho de 2010. p. 4.

${ }^{9}$ Este valor não tem uma justificativa técnica que forneça garantias de que a proteção das margens será obtida com esta faixa de proteção. Consideração obtida da Nota Técnica expedida pela $4^{\mathrm{a}}$ Câmara de Coordenação e Revisão do Ministério Público Federal acerca do Substitutivo de Lei nº 1876/1999, em 28 de junho de 2010. ${ }^{10}$ Lei $\mathrm{n}^{\circ} .4 .771 / 1965$, art. $1^{\circ}, \S 2^{\circ}$, III: "Reserva Legal: área localizada no interior de uma propriedade ou posse rural, excetuada a de preservação permanente, necessária ao uso sustentável dos recursos naturais, à conservação e reabilitação dos processos ecológicos, à conservação da biodiversidade e ao abrigo e proteção de fauna e flora nativas.
} 
Pagamento por serviços ambientais (PSA) como ferramenta efetiva à aplicabilidade do Código Florestal brasileiro: uma proposta combativa ao projeto de lei $\mathrm{n}^{\circ}$. 1876/99. Relatos da experiência pioneira de PSA no município de Londrina-PR

desta para imóveis rurais com área de até quatro módulos fiscais ${ }^{11}$, enquanto que nas propriedades superiores a esta medida, a reserva legal deverá ser recuperada apenas em relação à área que exceder os 4 (quatro) módulos fiscais e não com base na área total do imóvel ${ }^{12}$.

Outra significativa mudança cinge-se à compensação da Reserva Legal, no qual haverá a possibilidade da compensação ocorrer adotando-se o critério único da semelhança de bioma ${ }^{13}$, e não mais a exigência de mesma fitofisionomia ou localização na mesma bacia hidrográfica, raciocínio que considera a importância ecológica e a biodiversidade.

Permitir-se-á, ainda, o plantio de espécies exóticas na recomposição da Reserva Legal a partir de parâmetros técnicos adotados em lei estadual ou distrital, o que viabilizará a descaracterização da vegetação nativa das áreas recompostas, hipótese vedada pelo Código Florestal em voga. Cabe ressaltar também que o PL 1876/99 permitiu que a localização da Reserva Legal no interior do imóvel possa ser a livre arbítrio do proprietário ou possuidor, salvo quando houver prévia determinação do órgão ambiental competente do SISNAMA.

Prognostica o artigo 18 e incisos ${ }^{14}$ do projeto em exame, a possibilidade dos Estados aprovarem legislação específica sobre Zoneamento Ecológico-Econômico (ZEE), para que seus respectivos Poderes Executivos possam reduzir, para fins de regularização ambiental, a Reserva Legal dos imóveis situados nas diversas partes do Brasil.

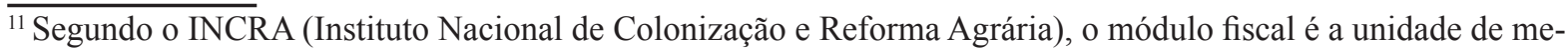
dida expressa em hectares fixada para cada município considerando fatores como: o tipo de exploração predominante no município; a renda obtida com a exploração predominante; outras explorações existentes no município que, embora não predominantes, sejam significativas em função da renda ou área utilizada, e, por fim, o conceito de propriedade familiar. As propriedades com até 4 módulos fiscais variam de 20 a 440 hectares, dependendo da região do país. Assim, a pequena propriedade rural é imóvel rural de área compreendida entre 1 (um) e 4 (quatro) módulos fiscais; a média propriedade é o imóvel rural de área compreendida entre 4 (quatro) até 15 (quinze) módulos fiscais; a grande propriedade é o imóvel rural de área superior a 15 módulos fiscais. Disponível em $<\mathrm{http}: / /$ www.incra.gov.br/portal/index.php?option $=$ com_content\&view $=$ category\&layout=blog\&id $=153 \& I t e m i d=182>$ Acesso em 29/09/2010.

${ }^{12}$ A título de exemplo, se determinada propriedade contiver 10 (dez) módulos fiscais, a sua Reserva Legal será calculada sobre os 6 (seis) módulos fiscais, e não mais sobre o total (10 MF).

${ }^{13} \mathrm{O}$ conceito de bioma é muito amplo, levando a situações em que propriedades localizadas no bioma Mata Atlântica podem ser utilizadas para compensar Reserva Legal de outra localizada em qualquer um dos 15 estados da federação em que ocorre Mata Atlântica, por exemplo. Consideração extraída da Nota Técnica expedida pela $4^{\text {a }}$ Câmara de Coordenação e Revisão do Ministério Público Federal acerca do Substitutivo de Lei no ${ }^{\circ}$ 1876/1999, em 28 de junho de 2010. p. 6.

${ }^{14}$ PL 1876/1999, artigo 18: "Quando indicado pelo Zoneamento Econômico Ecológico - ZEE, na forma do inciso II do art. $9^{\circ}$ da Lei no .6 .938 , de 31 de agosto de 1981, o Poder Executivo poderá: I- reduzir para, fins de regularização ambiental, a Reserva Legal de imóveis situados em área de formação florestal localizada na Amazônia Legal para até cinqüenta por cento da propriedade; II- reduzir, para fins de regularização ambiental, a Reserva Legal de imóveis situados em área de formação savânica na Amazônia Legal para até vinte por cento da propriedade; III- ampliar as áreas de Reserva Legal, em até cinqüenta por cento dos percentuais previstos nesta lei nos imóveis situados fora da Amazônia Legal".
} 
Considerável alteração que merece ressalva refere-se à inclusão da Área de Preservação Permanente (APP) no cômputo da Reserva Legal (RL), que propiciará situações em que as APPs existentes na propriedade sejam suficientes ou próximas do percentual previsto para a região ${ }^{15}$. Cumpre respaldar que o código atual permite esta circunstância ${ }^{16}$ apenas em casos em que a soma da vegetação nativa em área de preservação permanente e de reserva legal ultrapassar a $80 \%$ (oitenta por cento) da propriedade localizada na Amazônia Legal, 50\% (cinqüenta por cento) da propriedade rural situada nas demais regiões do país, $25 \%$ (vinte e cinco por cento) da pequena propriedade rural.

Conjeturado igualmente pela proposta em tela, o denominado Programa de Regularização Ambiental (PRA) - articulado nos artigos 24 a 27 do PL 1876/99 - está previsto para ser elaborado pela União, Estados-membros e Distrito Federal, tendo o prazo de 5 (cinco) anos a ser aplicado às áreas que tiveram vegetação nativa suprimida antes de 22 de julho de 2008 . A possível justificativa para a prescrição deste lapso temporal é a entrada em vigor do Decreto Federal no . 6.514 de 22 de julho de $2008^{17}$, que dispõe sobre as infrações e sanções administrativas ao meio ambiente, bem como sobre o processo administrativo federal para apuração de tais infrações. No entanto, as tipificações contidas no decreto supra mencionado já eram disciplinadas em momento anterior pelo Decreto Federal no ${ }^{\circ}$ 3.919/2001 (que dispunha sobre as sanções aplicáveis às atividades lesivas ao meio ambiente). Assim, a baliza temporal determinada pelo PL 1876/99 é aleatória e beneficiadora daqueles cidadãos que descumpriram a legislação ambiental até o presente ${ }^{18}$.

Apesar do Programa de Regularização Ambiental (PRA) objetivar a adequação ambiental das propriedades ou posses que não satisfizeram as devidas Reservas Legais e Áreas de Preservação Permanente, é perceptível a flexibilização trazida pelo novo texto, uma vez que se eximem das medidas previstas pelo PRA as áreas rurais consolidadas no tocante às Áreas de Preservação Permanente (artigo 24, $\S 3^{\circ}$, PL 1876/99) ${ }^{19}$.

Nota-se que a pretensa lei florestal modifica o parâmetro de responsabilidade pela ${ }^{15}$ Para melhor ilustração, podemos exemplificar que uma propriedade tenha a obrigação legal de manter $20 \%$ da sua área com Reserva Legal e que tenha 10\% deste imóvel com APP. Neste caso, a área efetiva de RL obrigatória será de $10 \%$ e não mais $20 \%$. Ou seja, a medida prevista no PL 1876/99 visa preferencialmente reduzir a conta das áreas de RL que estão hoje ilegalmente desmatadas e ocupadas, premiando aqueles que descumpriram a legislação vigente. Elucidação extraída da Nota Técnica e Política - As mudanças propostas no Código Florestal Brasileiro. TEIXEIRA, Gérson; CARDOSO, Alessandra. Brasília, 2010. p.6. Disponível em < http://www.scribd. com/doc/33417793/As-Mudancas-Propostas-No-Codigo-Florestal-Brasileiro-\%E2\%80\%93-Nota-Tecnica-ePolitica $>$. Acesso em 29/09/2010.

${ }^{16}$ Este benefício encontra-se no artigo $16, \S 6^{\circ}$, incisos I, II e III, do Código Florestal vigente (Lei $n^{\circ}$.

4.7771/1965).

${ }^{17}$ PL 1876/1999, art. 24, $\$ 1^{\circ}$.

${ }^{18}$ Nota Técnica expedida pela $4^{a}$ Câmara de Coordenação e Revisão do Ministério Público Federal acerca do Substitutivo de Lei $\mathrm{n}^{\circ} .1876 / 1999$, em 28 de junho de 2010. p.7.

${ }^{19}$ Tal postura contribui para o fortalecimento do desrespeito à legislação e contraria os esforços que os órgãos públicos brasileiros e a sociedade têm empreendido para conferir efetividade à legislação ambiental. Consideração extraída da Nota Técnica expedida pela $4^{\mathrm{a}}$ Câmara de Coordenação e Revisão do Ministério Público Federal acerca do Substitutivo de Lei $n^{\circ} .1876 / 1999$, em 28 de junho de 2010. p. 7. 
Pagamento por serviços ambientais (PSA) como ferramenta efetiva à aplicabilidade do Código Florestal brasileiro: uma proposta combativa ao projeto de lei $\mathrm{n}^{\circ}$. 1876/99. Relatos da experiência pioneira de PSA no município de Londrina-PR

recuperação dos danos ambientais, já que transfere ao Poder Público a obrigação primária pela restauração de áreas devastadas ilegalmente, uma vez que os dispositivos do projeto de lei ( artigo $24, \S 5^{\circ}$; 27 e seguintes) estabelecem que os Estados indicarão o orçamento dos investimentos realizados, as fontes dos recursos e o cronograma de implementação. Por outro lado, os proprietários rurais ficarão desonerados de adotar qualquer medida de recuperação de sua vegetação enquanto os Estados não executarem o Programa de Regularização Ambiental.

Pelas anotações expostas até o momento, percebe-se que inúmeros são os pontos discrepantes do Projeto de Lei 1876/1999 em relação ao Código Florestal vigente, o que demonstra, de pronto, que tal projeto é resultado de uma imensa pressão do setor agropecuário brasileiro, que, através da sua robusta bancada no cenário legislativo, defende ser a conservação das florestas o verdadeiro empecilho à expansão econômica do país.

Com o fito de refutar as argumentações inseridas nesse contexto, o presente estudo pretende delinear nas linhas subseqüentes o conceito de Pagamento por Serviços Ambientais (PSA) como um instrumento não só capaz de revelar a viabilidade de manutenção do Código Florestal brasileiro, mas, sobretudo, comprovar, através de casos concretos, que esta alternativa já vem consignando sua efetividade.

\section{PAGAMENTO POR SERVIÇOS AMBIENTAIS (PSA): CONCEITUAÇÃO E PERSPECTIVA}

É sabido que a natureza é provedora de serviços ao homem. Parte destes serviços prestados pelo meio ambiente são denominados "serviços ambientais" ou "serviços ecológicos" (ALTMANN; RECH, 2009, p.80). Sob a lógica de que a sociedade humana é completamente dependente dos serviços prestados pela natureza e que, em decorrência de muitos ecossistemas encontrarem-se degradados na atualidade, e, por conseguinte, deficientes na prestação desta contrapartida, tem-se evidenciado uma significativa valorização dos serviços ambientais.

A constatação desta valorização dos serviços oferecidos pelo meio ambiente apóia-se aos princípios do poluidor-pagador, do usuário-pagador e do protetor-recebedor, estando este último vinculado à idéia de que o agente público ou privado que protege um bem natural em benefício da comunidade deve receber uma compensação financeira como incentivo pelo serviço de proteção ambiental efetuado (BASTOS, 2007, p. 288).

Altmann e Rech (2009, p.85) esclarece que “os princípios de Direito Ambiental que orientam a proposta de cobrança e pagamento pelos serviços ambientais são o princípio da pre- 
venção e o princípio do usuário-pagador". Tal assertiva funda-se no fato de que pelo primeiro busca-se evitar o colapso dos biomas que fornecem os serviços ambientais; enquanto que o segundo configura uma medida pedagógica que intui evitar o desperdício e promover a prevenção.

É conveniente ao estudo destacar que os pagamentos por serviços ambientais desvinculam-se da crua idéia de "mercantilizar" o meio ambiente e todas as suas complexas interações. Basicamente, a noção deste instituto abarca uma nova concepção que, por sua vez, estriba-se em dois pilares: o didático, com o fito de conscientizar os privilegiados pelos serviços; e o valorativo, que objetiva valorizar propriamente aquele que auxiliou na preservação ambiental (ALTMANN; RECH, 2009, p. 85).

Basicamente, define-se Pagamento por Serviços Ambientais (WUNDER, 2008, p. 11):

[...] transação voluntária na qual o serviço ambiental bem definido ou uma forma de uso da terra que possa segurar este serviço é comprado por pelo menos um comprador de pelo menos um provedor sob a condição de que o provedor garanta a provisão deste serviço.

Pela conceituação acima descrita, o provedor de serviços ambientais poderá ser apenas quem demonstra domínio sobre o serviço ambiental, sendo capaz de garantir sua linear provisão durante o período definido. Mediante isto, o grupo de potenciais provedores poderá ser pessoas ou entidades habilitadas para tanto.

Em contrapartida, a definição exata do serviço prestado visa assegurar a melhor operacionalização do mesmo, já que quanto menos tangível mais difícil torna-se a atribuição de unidades mensuráveis deste serviço (WUNDER, 2008, p.30).

A experiência tem mostrado que a maior parte dos sistemas pioneiros de PSA é fixada em âmbito local, embora haja vastas experiências com planejamentos nacionais que têm sido implementados desde 1985 nos Estados Unidos e, 1996, na Costa Rica.

A partir do ano 2000, o Brasil consignou pioneiros projetos na Amazônia, a exemplo do Programa de Desenvolvimento Socioambiental da Produção Familiar Rural - Proambiente - que efetuou atividades relacionadas a compensações comunitárias pela prestação de serviços ambientais para pequenos produtores na região, sendo implantado em data recente o Programa Bolsa Floresta que tem como ponto primordial a tentativa de reduzir o desmatamento em unidades de conservação. 
Pagamento por serviços ambientais (PSA) como ferramenta efetiva à aplicabilidade do Código

Florestal brasileiro: uma proposta combativa ao projeto de lei $\mathrm{n}^{\circ}$. 1876/99. Relatos

da experiência pioneira de PSA no município de Londrina-PR

Os efetivos resultados obtidos em algumas regiões do país pela prática do pagamento por serviços ambientais serão abordados posteriormente em trato específico.

Convém enaltecer o contexto legislativo atinente a este tema. O Projeto de Lei $\mathrm{n}^{\mathrm{o}}$. 5.487/2009, localizado no Congresso Nacional, objetiva instituir a Política Nacional dos Serviços Ambientais, o Programa Federal de Pagamento por Serviços Ambientais, bem como elencar formas de controle e financiamento que viabilizem dito programa. Citado projeto de lei foi apensado a diversas propostas de lei que discorrem sobre a temática.

\section{PAGAMENTO POR SERVIÇOS AMBIENTAIS COMO FERRAMENTA À EFETIVIDADE DO CÓDIGO FLORESTAL BRASILEIRO}

A discriminação dos principais dispositivos trazidos pelo Projeto de Lei nº . 1876/1999 e sua correspondência em relação aos preceitos do Código Florestal vigente permitiram um superficial enfrentamento desta questão que tem enorme significância no cenário atual.

Nesse sentido, há, de um lado, o Código Florestal, de relevância internacional, que veio para tutelar a sociedade através da garantia de sua qualidade de vida, assegurando a preservação dos mananciais hídricos, a regularidade das chuvas, a conservação da biodiversidade, o controle dos gases do efeito estufa, a manutenção dos ricos biomas nacionais, e, dentre outros, o sustento os ciclos de vida da economia no ambiente rural e urbano. Além disso, a lei florestal brasileira carregou em suas linhas o caráter eminentemente coletivo e difuso do bem ambiental, e por isso, foi capaz de influenciar no texto da Constituição Federal de 1988 e de conferir as formas de se exercer a função social da propriedade (JODAS, 2010, p.4 $)^{20}$.

De outro lado, o Projeto de Lei 1876/1999 que estabelece mudanças consideráveis no Código em voga, nítido reflexo da insatisfação do setor ruralista brasileiro que ainda acredita ser o território nacional fonte de inesgotáveis recursos, que a tutela das Áreas de Preservação Permanente e Reserva Legal são obstáculos ao desenvolvimento econômico, sendo, em suma, o Código Florestal infinito limitador das atividades produtivas do campo.

De maneira formal, a maior parte das considerações iniciais do PL 1876/1999 discorridas pelo relator Aldo Rebelo (PC do B/ SP) focam-se, basicamente, na inaplicabilidade e inviabilidade do Código Florestal.

\footnotetext{
${ }^{20}$ A função social da propriedade, prevista nos artigos $5^{\circ}$, XXIII; 170, III; 186 da Constituição Federal, acopla a idéia de limitar o uso do imóvel pelo proprietário a fim de que diversos fatores sociais sejam respeitados, tais como o aproveitamento racional e adequado dos recursos naturais. Desta forma, o Código Florestal em vigor trouxe a perspectiva de que as florestas e demais formas de vegetação do país são bens de interesse comum a todos os brasileiros, sem distinção, e que, independentemente do local onde estes recursos florestais se encontram, eles precisam ser preservados.
} 
Indo de encontro às concepções defendidas pelos propulsores do PL 1876/99, o Pagamento por Serviços Ambientais (PSA), instituído em diversas regiões do país, tem demonstrado resultados extremamente relevantes à aplicabilidade da principal lei florestal brasileira.

Tanto é verdade, que programas pioneiros de PSA foram implantados em 2006 na Amazônia, vinculando serviços ambientais ligados ao carbono, água, qualidade do solo e biodiversidade, havendo, em contrapartida, pagamentos pelo desmatamento evitado, melhorias nas práticas agrícolas e toneladas de carbonos capturados (WUNDER; 2008, p. 34). Estas modalidades de transações realizadas ocorreram em escala federal, estadual e local no estado do Amazonas ${ }^{21}$.

Pode-se afirmar que os programas ProAmbiente e Bolsa Floresta ${ }^{22}$ trouxeram maior relevância no contexto do PSA no Amazonas. No caso do Bolsa Floresta , fica claro que o objetivo primordial finca-se na política de mudanças climáticas, consistindo na redução de emissões causadas pelo desmatamento. O ProAmbiente, em outra vertente, não estabeleceu uma nítida distinção entre os serviços ambientais prestados, podendo abranger objetivos vinculados à captura do carbono, redução do desmatamento, restabelecimento das funções hídricas e conservação da biodiversidade (WUNDER, 2008, p. 35).

Em outras regiões do país como a região Sudeste: o estado do Espírito Santo, que promulgou o Decreto Estadual no. 2168-R/2008, que aprova o Regulamento do Programa de Pagamento por Serviços Ambientais prestados pela cobertura florestal na conservação e incremento na qualidade e disponibilidade hídrica; Minas Gerais, no município de Extrema ${ }^{23}$, a bacia do rio Jaguari desde 2007 abriga o Programa Produtor de Água em parceria com diversas instituições, no qual se tornou responsável por grande parte do abastecimento da capital paulista; no Rio de Janeiro, na bacia do rio Guandu; em São Paulo, nas microbacias do Rio Moinho e Cancã,

\footnotetext{
${ }^{21}$ O Programa ProAmbiente abarcou 400 famílias em 10 pólos pioneiros (HALL, 2007; VIANA et al., 2006; MEDEIROS et al., 2007; apud WUNDER et al. 2008). O Bolsa Floresta, do governo estadual, albergou cerca de 8500 famílias (Governo do Amazonas, 2007; apud WUNDER et al., 2008). O PLANTAR capturou toneladas de carbono e teve como comprador a Agência Internacional Prototype Carbon Fund, abrangendo 2.300 hectares (MAY et al., 2003; apud WUNDER et al., 2008).

${ }^{22}$ O Programa Bolsa Floresta foi instituído pela Lei Estadual sobre Mudanças Climáticas (Capítulo IV, artigo 5, II), para o pagamento por serviços e produtos ambientais às comunidades tradicionais das Unidades de Conservação pelo uso sustentável, a conservação e proteção dos recursos naturais assim como para incentivar políticas voluntárias de redução de desmatamento.Disponível em < http://www.florestavivaamazonas.org.br/servicos_ambientais.php >. Acesso em: 06/10/2010.

${ }^{23}$ A prefeitura de Extrema/MG também aprovou lei municipal que remunera os agricultores com recursos do próprio caixa da cidade. Hoje 49 proprietários de terra no município recebem uma quantia que varia de $\mathrm{R} \$ 75$ a R\$ 169 por hectare/ano por práticas de conservação do solo e manutenção de matas. Minas Gerais teve o projeto de lei no 952/07, batizado de "Bolsa Verde", aprovado em 2008 pela Assembléia Legislativa e que aguarda regulamentação. Disponível em < http://www.ecodebate.com.br/2009/09/28/primeiras-iniciativas-de-pagamento-porservicos-ambientais-saem-do-papel-em-diversas-regioes-do-pais/ > . Acesso em: 07/10/2010.
} 
Pagamento por serviços ambientais (PSA) como ferramenta efetiva à aplicabilidade do Código Florestal brasileiro: uma proposta combativa ao projeto de lei $\mathrm{n}^{\circ}$. 1876/99. Relatos da experiência pioneira de PSA no município de Londrina-PR

localizadas nas cidades de Joanópolis e Nazaré Paulista. Também na região Centro-Oeste, no Ribeirão Pirapau, do Distrito Federal ${ }^{24}$.

Na região Sul do Brasil, destaque para o estado do Paraná, que apresenta dois municípios pioneiros na implantação do PSA: Apucarana, na bacia do rio Pirapó, promulgador do Projeto Oásis; e Londrina, na bacia do rio Tibagi, projeto a ser especificado no próximo tópico.

Cumpre, por ora, assinalar que o PL 1876/99, almejado pelo setor agrário brasileiro, é certamente uma tentativa de refutar uma realidade presente nos últimos anos: a efetividade do Código Florestal.

A constatação de que diversas regiões do país, em graus expressivos, têm mobilizado a sociedade civil organizada junto ao Poder Público e obtido significativo êxito na consecução das políticas públicas ambientais, estando aí inseridos os Pagamentos por Serviços Ambientais (PSA), demonstra claramente que a continuidade destes mecanismos deve ser incentivada e que o Código Florestal vigente apresenta plena capacidade de execução em todos os seus termos.

Em decorrência da quantidade de projetos e programas de PSA em implantação nas diversas regiões do país, o presente estudo concentrará específico enfoque no Programa de Recuperação de Vegetação Ciliar e Reserva Legal do Município de Londrina- PR, com o fito de comprovar, ao final, que a aplicabilidade da lei 4.771/1965 já existe.

\section{PROGRAMA DE RECUPERAÇÃO DE VEGETAÇÃO CILIAR E RESERVA LEGAL DO MUNICÍPIO DE LONDRINA - PARANÁ}

A ONG MAE - Meio Ambiente Equilibrado - associação civil sem fins lucrativos e de interesses estatutários vinculados à defesa do meio ambiente e dos interesses difusos e coletivos - atua na cidade de Londrina desde o ano de 2001, sendo composta, genericamente, por uma equipe de atuação multidisciplinar. Em 2006, desenvolveu um projeto relacionado à conservação dos recursos naturais intitulado "Na Pegada do Parque - do Parque Arthur Thomas ao Tibagi - Projeto de Corredor Ecológico" , que tem como principal objetivo a conexão dos fragmentos florestais em torno das unidades de conservação norte - paranaenses, valorizando a biodiversidade regional e a preservação de animais de médio e grande porte ali encontrados (alguns deles ameaçados de extinção no Paraná) e que necessitam de florestas para sobreviver. A parceria de empresas, órgãos e pessoas físicas com o Projeto "Na Pegada do Parque" permitiu identificar, quantificar e ofertar aos proprietários de terras ao longo do corredor supra descrito a recomposição das matas ciliares e o cumprimento das Reservas Legais.

\footnotetext{
${ }^{24}$ Mais informações disponíveis em < http://www.infoescola.com/ecologia/pagamento-por-servicos-ambientais-
} psa $>$. Acesso em: 07/10/2010. 
Em meio a todo envolvimento e repercussão entre diversas entidades públicas e privadas, no ano de 2009 é assinada uma força-tarefa, em que, coordenado pela Promotoria de Defesa do Meio Ambiente de Londrina, instituiu-se o Programa de Recuperação de Vegetação Ciliar e Reserva Legal do Município de Londrina - PR que agregou diversas instituições, tais como o Instituto Ambiental do Paraná (IAP), Conselho Municipal do Meio Ambiente (CONSEMMA), Secretaria Municipal do Meio Ambiente (SEMA), a própria ONG MAE, dentre muitas ou$\operatorname{tras}^{25}$, com o objetivo de diagnosticar, recuperar e monitorar Áreas de Preservação Permanente (APPs) e de Reserva Legal (RL) no Município de Londrina.

O Projeto "Na pegada do Parque" passou a integrar conjuntamente toda a complexidade do Programa, assumindo a ONG MAE o objetivo de plantar 40 mil mudas em pequenas propriedades rurais com hipossuficiência econômica ${ }^{26}$.

O Programa de Recuperação de Londrina adotou regiões prioritárias para realizar sua ação conjunta: as bacias hidrográficas do Ribeirão Cambé e Três Bocas, no trecho de interligação das unidades de conservação do Parque Municipal Arthur Thomas e Parque Ecológico Daisako Ikeda, até o encontro com o Baixo Tibagi, totalizando uma porção de 30 quilômetros pelo curso dos rios, abrangendo uma área de aproximadamente 200 hectares de matas ciliares; e, ainda, a bacia hidrográfica do Ribeirão dos Apertados, no trecho de conectividade entre a unidade de conservação Parque Estadual Mata dos Godoy até o Baixo Tibagi.

Além de todo o objetivo traçado que já mobiliza diversas entidades do Paraná, várias foram as estratégias adotadas no meio do caminho: realização de visitas e coleta de dados nas propriedades - quantificando-as e qualificando-as devidamente - elaboração do Plano de Manejo Florestal para cada uma das propriedades abarcadas pelo Programa, plantio e recuperação de áreas já degradas.

A aliança existente entre as metas do Projeto "Na Pegada do Parque" com o Programa de Recuperação de Vegetação Ciliar e Reserva Legal do Município de Londrina-PR potencializam a identificação de iniciativas no sentido de promover na comunidade a união entre grupos de pequenos agricultores para o associativismo ou cooperativismo com mote ecológico, de geração de renda ou de sustentabilidade; promoção de agroecologia e sistemas agroflorestais sustentáveis.

${ }^{25}$ Compõem igualmente o Programa de Londrina: a Secretaria Municipal de Agricultura, Secretaria do Estado de Meio Ambiente, ONG Tudo Verde, ONG Patrulha das Águas, Polícia Ambiental, Laboratório de Recuperação de Ecossistemas (LABRE), Universidade Estadual de Londrina (UEL), Universidade Norte do Paraná (UNOPAR), Universidade Federal Tecnológica do Paraná (UTPR), Superintendência de Desenvolvimento de Recurso Hídricos e Saneamento Ambiental (SUDERHSA),

${ }^{26}$ Os pequenos produtores rurais, majoritariamente, não têm condições mínimas de arcar sozinhos com o ônus da preservação ambiental. Justifica-se esta alusão quando se observa que os instrumentos necessários para a regularização de suas Áreas de Preservação Permanente e Reserva Legal demandam tempo e custos, já que os pequenos agricultores trabalham para si mesmos na condição de "autônomos", o que, obviamente, implica prejuízos diretos na sua produção agrícola diária, principal fonte de renda. 
Pagamento por serviços ambientais (PSA) como ferramenta efetiva à aplicabilidade do Código Florestal brasileiro: uma proposta combativa ao projeto de lei $\mathrm{n}^{\circ}$. 1876/99. Relatos da experiência pioneira de PSA no município de Londrina-PR

É reconhecido, assim, que a livre disposição do pequeno proprietário rural para integrar um complexo programa de gestão participativa no Município de Londrina-PR implicará com que ele automaticamente cumpra a legislação ambiental em vigor, em especial o SISLEG/ PR - Sistema de Manutenção, Recuperação e Proteção da Reserva Florestal Legal e Áreas de Preservação Permanente ${ }^{27}$ e o Código Florestal.

Outro importante objetivo traçado no Programa de Recuperação da Vegetação Ciliar e Reserva Legal do Município de Londrina-PR é a remuneração aos pequenos proprietários rurais pelos serviços ambientais prestados com a recuperação vegetal. A ferramenta da remuneração pelos serviços ambientais deve ser avaliada como uma possibilidade de estimular a recuperação da vegetação ciliar e da reserva legal, no sentido de garantir e viabilizar a recuperação em casos de hipossuficiência econômica.

No tocante aos Pagamentos por Serviços Ambientais (PSA), o Programa prevê o investimento de $\mathrm{R} \$ 300.000,00$ reais (trezentos mil reais) até a conclusão do plantio (prevista para o final de 2010), sendo tal recurso proveniente de uma medida compensatória do Grupo Sonae, que foi revertida ao IAP - Instituto Ambiental do Paraná - para a implantação do Programa. Desta forma, a ONG MAE passou, a partir de Novembro de 2010, a remunerar produtores que plantaram a Reserva Legal e as Matas Ciliares em suas propriedades.

Em média, para recomporem suas áreas, os pequenos agricultores rurais cadastrados ao Programa precisam plantar entre 600 (seiscentos) a 3.000 (três mil) mudas, sendo que pelo plantio de floresta calcula-se efetivar o pagamento de pelo menos $\mathrm{R} \$ 1,5$ mil reais por ano, de forma provisória e durante dois anos, divididos por semestre. Assim, o Pagamento por Serviços Ambientais intui compensar economicamente o agricultor familiar pelo custo material, econômico e pessoal da recuperação das vegetações ciliares e reserva legal.

Além de toda inovação no aspecto de preservação ambiental das florestas e vegetações ciliares através do PSA, o Programa também adota como meta a diversificação dos cultivos e técnicas de agroecologia nas propriedades rurais, incentivando o aumento nos rendimentos do agricultor com o devido respeito à legislação ambiental. Este objetivo será traçado por meio do Plano de Manejo Florestal que vem sendo elaborado a cada pequena propriedade, tendo o escopo de propiciar um panorama da situação da área a ser reflorestada, indicando os seus potenciais ecológicos, além orientar o proprietário quanto às espécies nativas ou não propícias à sua área, e que, concomitantemente, possam gerar aferição econômica.

\footnotetext{
7 Prevê que até 2018 os índices percentuais de Reserva Legal do estado do Paraná deverão estar atingidos em $20 \%$ em todas as propriedades rurais.
} 
Todos estes aspectos destacados do Programa de Recuperação de Vegetação Ciliar e de Reserva Legal do Município de Londrina - PR - inovam no sentido de que procuram de alguma forma efetivar a aplicação da lei ambiental vigente, seja no âmbito constitucional ou na legislação infra. Não há a definição absoluta de que os Pagamentos por Serviços Ambientais (PSA) sejam o único remédio saneador das constantes irregularidades e atrocidades que ocorrem diariamente com as florestas e vegetações marginais brasileiras. No entanto, pelo que até o momento se expôs, a experiência internacional ou nacional com este instrumento remuneratório tem comprovado significativa efetivação dos ditames trazidos nas normas ambientais.

Evidencia-se assim, que no contexto sócio-econômico do pequeno agricultor familiar, principal responsável pelo abastecimento alimentar diário das populações urbanas brasileiras, os Pagamentos por Serviços Ambientais (PSA) mostram-se ferramentas relevantes, compatíveis e razoáveis para a concreta efetividade do Código Florestal brasileiro.

\section{CONCLUSÃO}

Mediante a exposição relatada nas linhas desta pesquisa, nota-se que o Projeto de Lei nº 1876/99, em trâmite na Câmara dos Deputados, denota expressivo interesse do setor agrárioruralista brasileiro na continuidade da expansão agrícola e no descumprimento da legislação ambiental, ainda crescente na atualidade. As principais disposições contidas no substitutivo supracitado constatam que, caso o referido projeto seja aprovado, a biodiversidade dos biomas brasileiros e a sadia qualidade de vida da sociedade estarão em risco.

Neste contexto, o Pagamento por Serviços Ambientais (PSA), recurso moderno que consiste na lógica de valorizar os serviços constantemente prestados pela natureza, tem sido uma ferramenta efetiva adotada por distintas regiões brasileiras, fruto da atuação conjunta entre a sociedade civil e o Poder Público que tem demonstrado meios eficazes de preservação dos ecossistemas do país.

O Programa de Recuperação de Vegetação Ciliar e Reserva Legal do Município de Londrina-PR é um exemplo concreto de que o incentivo a boas práticas agrícolas somado aos Pagamentos por Serviços Ambientais podem garantir a aplicabilidade do Código Florestal vigente. 


\section{REFERÊNCIAS}

ALTMANN, Alexandre; RECH, Adir Ubaldo (Org.). Pagamento por serviços ambientais: imperativos jurídicos e ecológicos para a preservação e a restauração das matas ciliares. Caxias do Sul: EDUCS, 2009.

ALTMANN, Alexandre. Pagamento por serviços ambientais: aspectos jurídicos para a sua aplicação no Brasil. In: CONGRESSO INTERNACIONAL DE DIREITO AMBIENTAL, 14., 2010, São Paulo. Florestas, mudanças climáticas e serviços ecológicos. São Paulo: Imprensa Oficial, 2010. v. 1.

BASTOS, Carolina Vieira Ribeiro de Assis. Instrumentos econômicos de proteção do meio ambiente: reflexões sobre a tributação e os pagamentos por serviços ambientais. Londrina: Scientia luris, 2007, v. 11. p. 279-293.

JODAS, Natália. Pagamentos por serviços ambientais (PSA) a pequenos agricultores rurais: uma nova perspectiva à preservação da biodiversidade. Considerações acerca do programa de recuperação de vegetação ciliar e reserva legal do município de Londrina - PR. In: CONGRESSO INTERNACIONAL DE DIREITO AMBIENTAL, 14., 2010, São Paulo. Florestas, mudanças climáticas e serviços ecológicos. São Paulo: Imprensa Oficial, 2010. v. 2.

MACHADO, Paulo Affonso Leme. Direito ambiental brasileiro. 12. ed. São Paulo: Malheiros, 2004.

MORAES, Luis Carlos Silva de. Código florestal comentado. 4. ed. São Paulo: Atlas, 2009.

SARLET, Ingo Wolfgang (Org.). Estado socioambiental e direitos fundamentais. Porto Alegre: Livraria do Advogado, 2010.

WUNDER, Sven et al. Pagamentos por Serviços ambientais: perspectivas para a Amazônia legal. Brasília: Ministério do Meio Ambiente, 2008. 